\title{
PARTICIPACIÓN DE LA GRAN EMPRESA EN LA POLÍTICA PÚBLICA DE ATENCIÓN A LAS VÍCTIMAS DEL CONFLICTO ARMADO EN COLOMBIA*
}

\author{
Andrés Mariño-Arévalo:" \\ Marcela Valencia-Toro ${ }^{* * * *}$
}

doi: 10.11144/Javeriana.cao28-50.pgep. Este artículo es producto de la investigación “Emprendimiento, instituciones y construcción de paz" financiado por la Universidad del Rosario. El artículo se recibió el 03/02/2015 y se aprobó el 30/05/2015. Sugerencia de citación: Mariño A., A. y Valencia T., M. (2015). Participación de la gran empresa en la política pública de atención a las víctimas del conflicto armado en Colombia. Cuadernos de Administración, 28 (50), 159-185. http:// dx.doi.org/10.11144/Javeriana.cao28-50.pgep

** Magister en Administración de la Universidad Nacional de Colombia, 2010. Profesor Principal de la Escuela de Administración de la Universidad del Rosario, Bogotá, Colombia.

Correo electrónico: andres.marino@urosario.edu.co

*** Estudiante de Doctorado en Estudios Políticos y Relaciones Internacionales de la Universidad Nacional de Colombia, Bogotá, Colombia.

Correo electrónico: mvalenciat@unal.edu.co 


\section{Participación de la gran empresa en la política pública de atención a las víctimas del conflicto armado en Colombia}

\section{RESUMEN}

Este artículo busca abrir un diálogo necesario para las ciencias administrativas: brindar herramientas a la empresa para responder a los cambios del entorno que generará la firma de un acuerdo de paz con grupos insurgentes. Para esta investigación se realizó trabajo de campo con el grupo Éxito, la Organización Ardila Lülle, Pan Pa'Ya y Aviatur, y se encontró un bajo conocimiento de la política pública de atención a víctimas y de sus formas de articulación. Las acciones realizadas por estas empresas no son sistemáticas con respecto a las víctimas, pero existen posibilidades de fortalecer su accionar planteando estrategias integrales que cubran los aspectos político, social y cultural, no sólo lo económico. Lo cual queda como propuesta para futuras investigaciones.

Palabras clave: empresa privada, construcción de paz, política pública, conflicto armado

Clasificación JEL: D22, D74, M48

\section{ABSTRACT}

This article aims at opening a much-needed dialogue between the administrative sciences. It seeks to give companies tools to prepare them for the societal changes that will come about once the peace treaty is signed between the Colombian government and the insurgent groups. For the purposes of this research, field work was conducted with the Éxito Group, the Ardila Lülle Organization, Pan Pa'Ya and Aviatur, and the findings indicated that there is a general low level of knowledge in regards to the public policies for the attention to victims and its articulation methods. Actions carried out by these companies are not systematic in regards to victims, although there are possible ways to strengthen their efforts by setting out integral strategies that can cover not only the economical but the political, social and cultural aspects. These may be further explored in future research.

Keywords: Private enterprise, peace building, public policy, armed conflict.

JEL Classification: D22, D74, M48

\section{Participação das grandes empresas na política pública de atenção das vítimas do conflito armado na Colômbia}

\section{Resumo}

Este artigo pretende abrir um diálogo necessário para as ciências administrativas: oferecer ferramentas à empresa para responderem às mudanças do ambiente que gerará a assinatura de um acordo de paz com grupos insurgentes. Para esta pesquisa, realizou-se um trabalho de campo com o grupo Éxito, a Organização Ardila Lülle, Pan Pa'Ya e Aviatur, no qual se constatou um baixo conhecimento da política pública de atenção a vítimas e de suas formas de articulação. As ações realizadas por essas empresas não são sistemáticas no que se refere às vítimas, mas existem possibilidades de fortalecerem seu agir propondo estratégias integrais que abranjam os aspectos político, social e cultural, não somente o econômico. Essa temática seria para futuras pesquisas.

Palavras-chave: empresa privada, construção da paz, política pública, conflito armado.

Classificação JEL: D22, D74, M48 


\section{Introducción}

El conflicto armado en Colombia es una de las realidades más complejas de la historia reciente de este país. Es difícil identificar una fecha de inicio de este conflicto contemporáneo, pero con el fin de dar mayor claridad al lector, se mencionarán algunos de los elementos fundamentales.

El periodo de "La Violencia", que en el imaginario de la mayoría de los colombianos comenzó el 9 de abril de 1948, fue en realidad un periodo que inició a finales de los años treinta, con diferentes hitos para los partidos políticos, en el que se dieron transformaciones fundamentales con respecto al sistema económico colombiano, específicamente con el fortalecimiento de las exportaciones cafeteras y la transformación de la estructura de tenencia de la tierra a partir del éxodo de campesinos de diferentes zonas del país (Silva y Valencia, 2013).

El 9 de abril de 1948 dio paso a la expansión de la violencia a todo el territorio nacionaly la consolidación de organizaciones leales a cada uno de los partidos: Los pájaros conservadores y las guerrillas liberales. La solución a la expansión de este fenómeno fue el acuerdo de elites que llevó a la dictadura del General Gustavo Rojas Pinilla, en el que se lograron los acuerdos de paz con las guerrillas liberales, que fueron traicionados, generando la política de persecución y eliminación sistemática de los combatientes desmovilizados.

Como parte de esta tradición de negociación de elites, la dictadura militar de Rojas Pinilla finalizó con los Acuerdos de Sitges, Benidorm y San Carlos, en los que se estableció el llamado Frente Nacional, acuerdo político que estableció la alternancia en la presidencia del país, y además la paridad en la repartición de la burocracia, lo que fortaleció el clientelismo y la corrupción. Pero además de esto, se convirtió en el caldo de cultivo de aparición de grupos guerrilleros pues el sistema político se cerró a cualquier opción política diferente a los partidos Liberal y Conservador.

En este contexto surgieron las Fuerzas Armadas Revolucionarias de Colombia (FARC) en 1964, después de la operación Marquetalia, operación militar contra las Repúblicas Independientes en la región del sur del Tolima. En este mismo año nació el Ejército de Liberación Nacional, guerrilla que se inspiró en la Revolución Cubana, y que realizó su primera acción militar en enero de 1965, en el departamento de Santander. El Ejército Popular de Liberación se fundó en 1967, con inspiración marxista leninista maoísta y que actuó principalmente en Antioquia, Urabá, Córdoba y Sucre. En el año 1969, después de 
las elecciones presidenciales en las que las acusaciones de fraude electoral fueron ignoradas, nació el Movimiento 19 de Abril, M-19, una guerrilla que actuó en zonas urbanas.

La acción de estos grupos guerrilleros se expandió por todas la geografía, dejando víctimas en todo el país. A esto se sumó la aparición en la década de 1980 de grupos paramilitares, que con financiación del narcotráfico, de grandes terratenientes y con la complacencia y ayuda de los gobiernos colombianos, se convirtieron en una máquina de guerra que desplazó y victimizó a otra gran cantidad de víctimas.

De acuerdo con cifras de CODHES entre 1985 y 2012 salieron desplazados de sus hogares 5.905.996 personas. A partir de la expedición de la Ley de Víctimas en el año 2011, el registro de víctimas en Colombia asciende a 6.043.473 personas (Revista Semana, 2014).

El escenario de las negociaciones de paz con la guerrilla de las FARC-EP iniciadas en el año 2012 planteó un nuevo reto a la sociedad colombiana: cómo buscar formas de participación de la sociedad que permitan la consolidación de una paz duradera, que implique la participación en la búsqueda de métodos para la integración de las víctimas en condiciones de dignidad.

En este marco uno de los temas que siguen pendientes es la generación de sinergias entre los sectores privado y público para la atención de víctimas, por lo que este artículo busca identificar algunas posibilidades de participación de la empresa privada en la política pública de atención a la población víctima, teniendo como horizonte teórico fundamental la relación entorno-empresa. Así, el objetivo general de esta investigación es identificar oportunidades de participación de la empresa privada en los ámbitos de intervención de la política pública de atención a la población víctima del conflicto armado, en su componente de atención integral, subcomponente de generación de ingresos y empleo.

Para lograr este objetivo se establecieron como objetivos específicos:

- Caracterizar la política pública de atención a la población víctima del conflicto armado en el componente de atención integral, subcomponente de generación de ingresos y empleo.

- Identificar las posiciones de grandes empresas con respecto a la ley de víctimas y posibilidades de participación en el componente de atención integral, subcomponente de generación de ingresos y empleo. 
- Comparar el diseño de la política pública de atención a la población víctima del conflicto armado en el componente de atención integral, subcomponente de generación de ingresos y empleo.

Dentro del diseño inicial de investigación se pretendió identificar las posiciones de grandes, medianos y pequeños empresarios, pero a pesar de los esfuerzos por obtener las entrevistas con medianos y pequeños empresarios no fue posible realizarlas.

La metodología del trabajo es cualitativa ya que el diseño de instrumentos buscó dar cuenta de las principales características de dos fenómenos sociales: la política pública de atención a la población desplazada y la posición de grandes empresarios con respecto a esta. Además, se utilizaron instrumentos de análisis de política pública, que permitieron establecer ámbitos de intervención y los avances de su implementación, y que buscó darle una mayor solidez al análisis de la relación entorno-empresa en lo político-reglamentario, en la medida en que entiende que la política pública implica la acción sistemática de diversas instituciones, desplegadas a partir de ámbitos de intervención, que no se limitan a lo que se declara en una ley. En la Tabla 1 se presentan los instrumentos de investigación, la fuente y su forma de análisis.

\section{Tabla 1}

Instrumento, fuente y forma de análisis de la investigación

\begin{tabular}{|c|c|c|}
\hline Instrumento & Fuente & Forma de análisis \\
\hline $\begin{array}{l}\text { Entrevista semi-estructurada } \\
\text { (se realizaron de forma perso- } \\
\text { nal, en la ciudad de Bogotá). }\end{array}$ & $\begin{array}{l}\text { Grandes empresarios colombianos } \\
\text { ubicados en la ciudad de Bogotá. }\end{array}$ & $\begin{array}{l}\text { Matriz de sistematización de entrevistas a } \\
\text { partir de las variables de diseño. } \\
\text { Identificación de las posiciones de los gran- } \\
\text { des empresarios. }\end{array}$ \\
\hline $\begin{array}{l}\text { Matriz de sistematización de } \\
\text { documentos de política pública. }\end{array}$ & $\begin{array}{l}\text { Publicaciones gubernamentales en- } \\
\text { tre } 1997 \text { y } 2014 \text {. }\end{array}$ & $\begin{array}{l}\text { Identificación de ámbitos de política pública. } \\
\text { Construcción de un contexto histórico sobre } \\
\text { la atención a población víctima. }\end{array}$ \\
\hline $\begin{array}{l}\text { Matriz de resultados de políti } \\
\text { pública. }\end{array}$ & $\begin{array}{l}\text { Publicaciones gubernamentales en- } \\
\text { tre } 1997 \text { y } 2014 \text {. }\end{array}$ & $\begin{array}{l}\text { Tabla de resultados. } \\
\text { Presentación de avances institucionales. }\end{array}$ \\
\hline $\begin{array}{l}\text { Matriz de comparación de en- } \\
\text { trevistas y política pública. }\end{array}$ & $\begin{array}{l}\text { Matriz de sistematización de entre- } \\
\text { - vistas. } \\
\text { Matriz de sistematización de docu- } \\
\text { mentos de política pública. }\end{array}$ & $\begin{array}{l}\text { Construcción de conclusiones y apartado de } \\
\text { análisis del documento. }\end{array}$ \\
\hline
\end{tabular}

Fuente: elaboración propia.

Teniendo en cuenta estos elementos iniciales el artículo se dividirá en cuatro partes: en primer lugar se presentará el marco conceptual de esta investigación a través de una 
perspectiva histórica de las concepciones de la relación entorno-empresa; en segundo lugar, el marco histórico, la descripción de ámbitos de intervención de la política pública de atención a la población desplazada y los avances en la implementación de los mismos; a continuación, se presentarán los hallazgos de las entrevistas realizadas; y por último, las conclusiones y recomendaciones.

\section{Relación entorno-empresa}

Para este abordaje conceptual se parte de una proposición fundamental en la comprensión de las ciencias administrativas: las organizaciones empresariales están sometidas permanentemente a diferentes interacciones. La visión sobre estas interacciones varía con el tiempo y la consolidación disciplinar. Las propuestas clásicas de la Administración se concentraban en la atención a las variables internas de la empresa, desde una perspectiva mecanicista comprendiendo al sistema organizacional empresarial como un sistema orientado a la búsqueda de la eficacia, caracterizado por su rigidez y estabilidad (Morgan, 1999; Lam, 2010; Sonntag, 2010). Sin embargo, esta visión ha evolucionado: la Teoría General de Sistemas de Bertalanffy (1989) involucró procesos de integración e interacción de los elementos que los componen, rompen la lógica mecanicista, entendiendo los sistemas como dinámicos. Posteriormente, autores como Sloan o Drucker, asumieron una orientación práctica, entendiendo a la empresa como un lugar de generación de recursos, pero que "no viven para sí mismas, son medios, son órganos sociales que pretenden la realización de esa tarea social" (Velásquez, 2002, p. 47).

Los procesos de consolidación de las economías capitalistas posteriores a la Segunda Guerra Mundial configuraron entornos relativamente estables, debido a la fortaleza de las políticas sociales que sostenían la estructura de los Estados de Bienestar, y la estabilidad propia de los procesos de consolidación de economías nacionales por medio de políticas proteccionistas. En ese contexto, se potenció el uso de herramientas de la estrategia, pensadas para articular acciones internas en la empresa con las necesidades del entorno, en el largo plazo, mediado por criterios de certidumbre y estabilidad, que llevaron a asumir posturas deterministas que no dan cuenta de la realidad empresarial, y de aquello que la rodea (Benhamu y Le Garrec, 2005).

Hasta este momento, las empresas tenían un papel reactivo ante las mutaciones del entorno, con respuestas adaptativas a las necesidades que surgieran por parte de éste, bajo una lógica de causa - efecto (Etkin y Schvarstein, 2005). Sin embargo, en este periodo de consolidación de las economías capitalistas, las grandes empresas y grupos empresariales 
adquirieron un poder económico y político importante, reconfigurando las relaciones entorno - empresa, generando impactos de doble vía que rompieron la linealidad existente. Lo anterior sumado a la nueva oleada de globalización y apertura de los mercados amplió el concepto de entorno de las empresas, desarrollando los elementos conceptuales que guían este artículo. No sólo se estudian las variables que inciden sobre el rendimiento de las empresas, sino aquellas que pueden ser incididas por estas últimas y que configuran el campo de acción, dando cuenta de una comprensión más amplia de las organizaciones empresariales, como sistemas inciertos alejados del equilibrio y la estabilidad (Navarro, 2000; Ferrandon, 2004).

En consecuencia con esto, Lemaire (1997) afirma que el entorno está compuesto por variables de tipo político reglamentario, socioeconómico y tecnológico, principalmente, tal como se puede observar en la Figura 1.

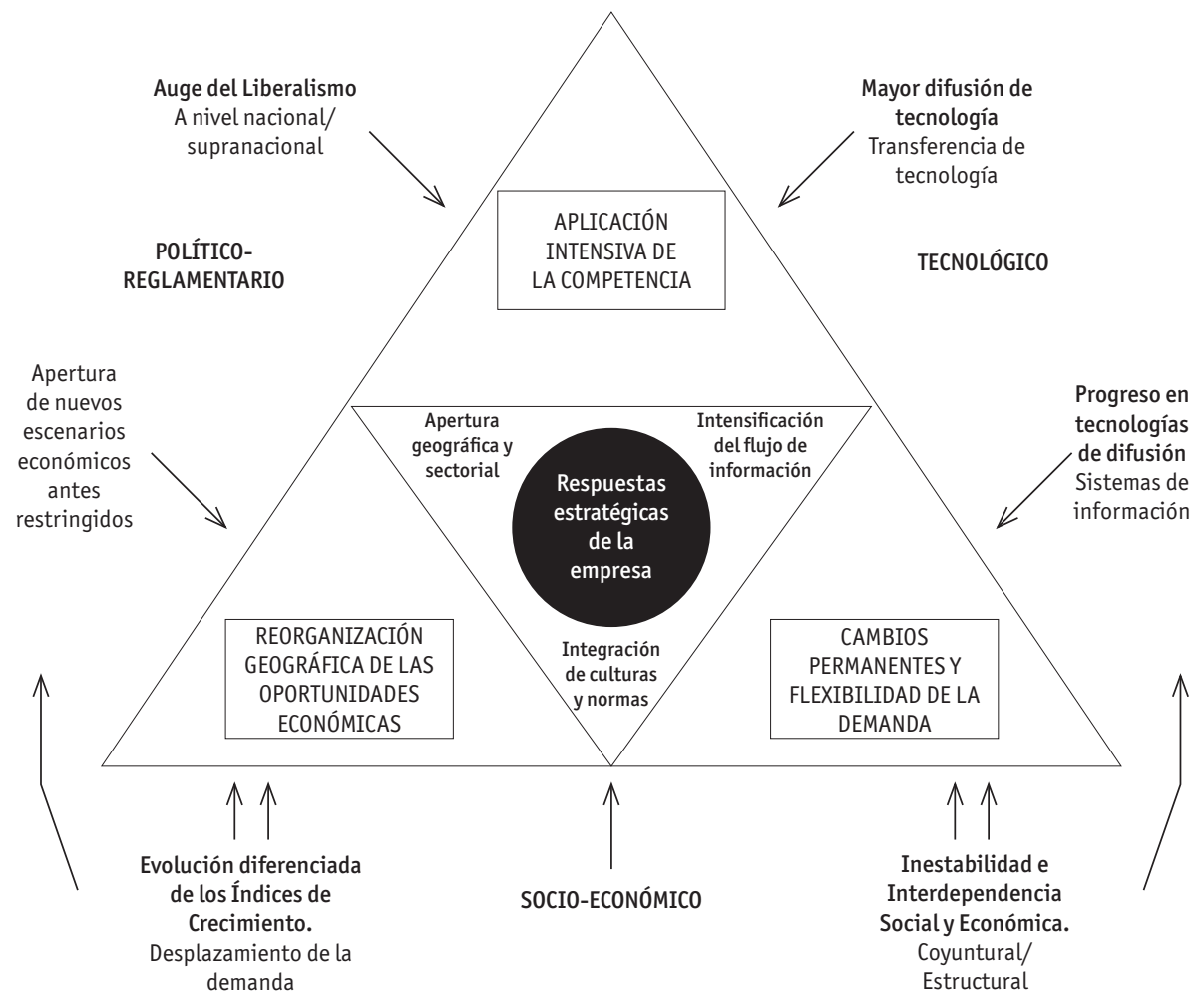

Figura 1. Mutaciones del entorno

Fuente: Rodríguez y Duque (2007). 
Dentro de esta configuración del entorno se asume que cada uno de los aspectos puede ejercer una presión sobre la empresa, y esta reaccionará a través de una respuesta estratégica a esa presión externa. A su vez, y en función del tamaño e incidencia de la empresa, se puede comprender la presión en una doble vía, asumiendo a la organización empresarial como un sistema con capacidad potencial para suscitar cambios en su entorno.

Para Krieger (2001, p. 251) las empresas - sin excepción- “están afectadas por el sistema legal, las leyes establecen gran parte de las condiciones operativas de muchas organizaciones. La estabilidad de las condiciones legales (...) aseguran y facilitan o dificultan los contextos en los cuales se desenvuelven las organizaciones", dando cuenta de la importancia que tienen los aspectos político reglamentarios en la definición de los marcos que delimitan el accionar de las organizaciones empresariales.

En este artículo se propone que no es sólo el entramado legal el que lleva a reacciones frente al entorno, sino las políticas públicas entendidas como una respuesta a una problemática social; la cual puede ser estudiada en cinco fases: identificación del problema, formulación de soluciones o acciones, toma de decisiones, implementación y evaluación. Esta visión tiene como ventaja la posibilidad de definir claramente el objeto de estudio del analista de política pública; pero al mismo tiempo, parte de una visión positivista de una acción acumulativa que limita los procesos de investigación, y deja de lado la interpretación que se haga de esta acción del Estado (Roth, 2003).

Los presupuestos del marco epistemológico, la comprensión de la racionalidad y las propuestas en términos de los métodos de investigación implican una comprensión de la política pública como una forma de moldear la interacción social, que determina una forma de distribución de recursos en la sociedad, pero que además da forma a lo que entendemos como necesidades sociales (Forester, 1989, 1993, 2009).

En consecuencia, se asume el enfoque de gestión por políticas, según el cual la política pública no se limita a su formulación en instancias como el congreso, sino que tiene que ver con la emergencia de un campo de intervención estatal y de sus trayectorias (Tapia, 2012, p. 104). En este marco es fundamental el concepto de referencial, que se entiende "como el conjunto de argumentos con los cuales se construye la imagen o representación de la realidad o situación a intervenir" (ibíd., p. 109).

El segundo concepto que permite establecer el puente entre la política pública y la relación entorno-empresa es el de campo organizacional, pues se entiende que este está 
compuesto por organizaciones que pertenecen a diferentes sectores de la administración pública y de diferentes sectores económicos, es decir organizaciones no estatales, pues en este se concreta la acción sobre una población determinada (Tapia, 2012).

Independientemente de la fuerza que asuma cada una de las variables que determinan el entorno, y sin importar la naturaleza y dimensión de la organización que se ve afectada por éste, las empresas “deben responder estratégica y dinámicamente a los cambios a los cuales se ven abocadas" (Rodríguez y Duque, 2008, p. 149). Esta respuesta estratégica debe verse materializada en acciones particulares para integrar los requerimientos del entorno, sus restricciones y delimitaciones, así como las necesidades, para asumir una tarea constante de proyección (López y Mariño, 2010).

\section{La política pública de atención a las víctimas en su componente de generación de ingresos}

En este apartado se encontrarán dos divisiones: en primer lugar, un abordaje histórico de la comprensión del problema social de las víctimas en Colombia desde el año 1997 hasta el año 2011; en la segunda parte se presentarán los resultados del componente de generación de ingresos de la política pública como eje de este trabajo.

\subsection{Las víctimas en Colombia entre 1997-2011}

El periodo de este primer apartado tiene como hito de inicio la expedición de la Ley 387 de 1997, primera herramienta jurídica que reconoció el fenómeno del desplazamiento forzado como una realidad del conflicto armado que debía ser atendido por el Estado a partir del diseño de una política pública. Esta realidad también determinó la creación de unas formas de coordinación institucionales importantes con el Sistema Nacional de Atención Integral a la Población Desplazada, y comités municipales que buscaban generar capacidades locales de atención a desplazados.

El diseño de la política pública se planteó a partir de tres componentes: prevención y protección, atención humanitaria de emergencia y estabilización socioeconómica (ACNUR, 2008). De estos componentes el que más se desarrolló en la implementación de la política pública fue el segundo, que consiste en ayudas que se entregan a desplazados en el momento de llegada al municipio receptor. 
El componente más importante en esta investigación es la estabilización socioeconómica, y en particular, la generación de ingresos. En un informe presentado por la Contraloría General de la Nación (2012) hay dos elementos fundamentales: en primer lugar, la implementación de la ruta de empleo no fue completada en la mayoría de casos; y en segundo lugar, esta no se articuló con una política de desarrollo que permitiera la sostenibilidad de los esfuerzos de emprendimiento.

La Sentencia T-025 de 2004 es vital para entender esta política pues estableció “El estado de cosas inconstitucional" con respecto a la situación de la población desplazada, que implica:

(i) la vulneración masiva y generalizada de varios derechos constitucionales que afecta a un número significativo de personas; (ii) la prolongada omisión de las autoridades en el cumplimiento de sus obligaciones para garantizar los derechos; (ii) la adopción de prácticas inconstitucionales, como la incorporación de la acción de tutela como parte del procedimiento para garantizar el derecho conculcado; (iii) la no expedición de medidas legislativas, administrativas o presupuestales necesarias para evitar la vulneración de los derechos; (iv) la existencia de un problema social cuya solución compromete la intervención de varias entidades, requiere la adopción de un conjunto complejo y coordinado de acciones y exige un nivel de recursos que demanda un esfuerzo presupuestal adicional importante; (v) si todas las personas afectadas por el mismo problema acudieran a la acción de tutela para obtener la protección de sus derechos, se produciría una mayor congestión judicial (Corte Constitucional de Colombia, 2004, párr. 8).

Esta sentencia se convirtió en un elemento fundamental que obligó al Estado colombiano a desarrollar acciones reales para la implementación de la política pública y atender un problema que superó la capacidad institucional y a un enorme sector de población en condiciones de desprotección. Sin embargo, la realidad de la política en términos de la construcción de una visión social sobre el problema fue muy limitado: creó un imaginario social de la población desplazada como otra parte de la población vulnerable del país, y no como víctimas que deberían recibir una restitución de sus derechos.

\subsection{Las víctimas en Colombia y un nuevo escenario de política pública}

Este apartado se centrará en la política pública que se desprende de la expedición de la Ley 1448 de 2011 Por la cual se dictan medidas de atención, asistencia y reparación integral a las víctimas del conflicto armado interno y se dictan otras disposiciones. Con 
este fin se presentará una descripción de los componentes de la política pública en general, para después desarrollar el subcomponente de empleo y generación de ingresos.

POLÍTICA PÚBLICA DE ATENCIÓN A LA POBLACIÓN VÍCTIMA DEL CONFLICTO ARMAD0 (Ley 1448 de 2011)
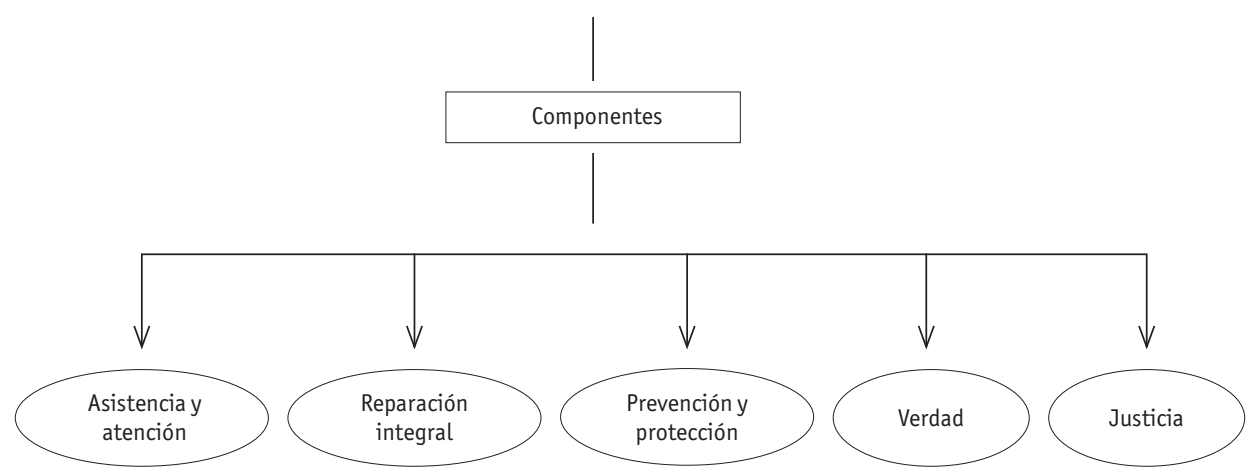

Figura 2. Componentes de la política pública de atención a víctimas del conflicto armado Fuente: elaboración propia a partir de DNP $(2011,2012)$ y la Ley 1448 de 2011.

Asistencia y atención: este componente busca responder a las necesidades de atención humanitaria, y "está dirigida a restablecer los derechos de las víctimas, garantizar las condiciones para llevar una vida digna y garantizar su incorporación a la vida social, económica y política, a través de un conjunto integrado de medidas, programas y recursos de orden político, económico, social, fiscal, entre otros" (DNP, 2011, párr. 55). Este componente busca dar atención a las víctimas en el momento inmediatamente posterior a los hechos victimizantes, a través del subcomponente de ayuda humanitaria para las víctimas y atención humanitaria para la población desplazada, medidas de asistencia funeraria, identificación, reunificación familiar, así como también educación y salud.

Reparación integral: busca cumplir con preceptos internacionales de restitución, indemnización, rehabilitación, satisfacción y garantías de no repetición, que se traducen en subcomponentes de restitución de tierras y de vivienda, indemnización por subsidio de vivienda, indemnización por vía administrativa, empleo y generación de ingresos, créditos y pasivos, y las garantías de no repetición.

Prevención y protección: este componente agrupa medidas que buscan prevenir violaciones de los Derechos Humanos e infracciones del DIH. 
Verdad: componente orientado a la construcción de una paz estable y duradera, fortaleciendo la perspectiva de reparación de víctimas, y responde a las necesidades de verdad histórica y verdad judicial. Los subcomponentes son Derechos Humanos y Memoria Histórica, y Mecanismo no judicial de Verdad histórica.

Generación de ingresos y empleo: el diseño de este componente en la política pública de atención a la población víctima del conflicto no es un nuevo planteamiento en la lógica de funcionamiento de la política pública, pues asume el diseño de la política pública de atención a la población desplazada.

El objetivo que se establece es "desarrollar e incrementar el potencial productivo de la población en situación de pobreza extrema y desplazamiento, aprovechando sus capacidades y creando oportunidades para que puedan acceder y acumular activos" (DNP, 2012, p. 37).

Así, la forma de medición que adoptó el Estado colombiano con respecto a este tema quedó consignada en el Auto 116/2008 de seguimiento a la Sentencia T-025/04, en el que se establecieron como indicadores de medición para generación de ingresos (i) superación de la línea de indigencia, (ii) superación de la línea de pobreza. Como indicadores complementarios, que implica que no son de obligatorio cumplimiento para el gobierno, se establecieron: jornada laboral, tipo de relación laboral, afiliación a seguridad social y riesgos profesionales, remuneración mínima y formalidad (Gómez, 2015).

Herazo y Sellamén (2010, p. 165) señalan que el programa de generación de ingresos tuvo como principales falencias: “(i) la desinformación estatal respecto de las organizaciones no gubernamentales y la influencia desacertada de los medios de comunicación, (ii) el enfoque errado de los componentes de atención, porque se han combinado con otros fenómenos como la pobreza histórica y estos son fenómenos con orígenes y características diferentes, (iii) la inexperiencia de los diseñadores de política pública, y (iv) el seguimiento inadecuado por parte de las organizaciones correspondientes".

Estas críticas llevan a identificar lo que puede considerarse la mayor debilidad con respecto a la política pública de atención a la población víctima del conflicto armado en el subcomponente analizado: no se realizaron medidas correctivas de estas falencias y se asumió un modelo que desde muchas perspectivas demuestra que no logra el goce efectivo de derecho. 
Pero a pesar de esto es necesario ahondar en la presentación del diseño actual, para lo que se presenta la ruta de atención a la población beneficiaria (Figura 3).

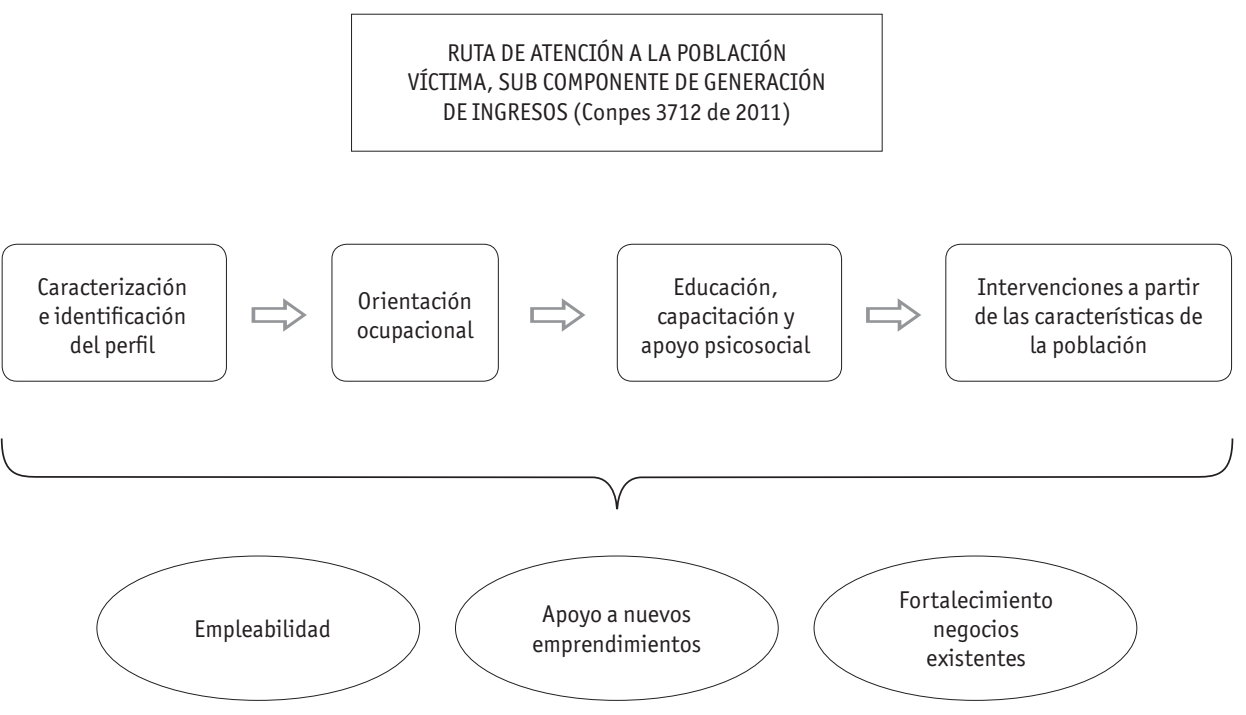

Figura 3. Ruta de atención a la población víctima

Fuente: elaboración propia a partir de DNP (2011).

De acuerdo con el Conpes 3712 de 2011 los criterios para la toma de decisiones con respecto al tipo de intervenciones a realizar después de seguir la ruta de atención en la zona urbana son: edad, nivel educativo, condición laboral y tipo de ocupación; en la zona rural: acceso a la tierra, tenencia formal de la tierra y ocupación agropecuaria. En términos de institucionalidad y sus acciones, un informe de la Procuraduría General presentó este escenario que se resume en la Tabla 2.

Lo que se infiere de la Tabla 2 es que el avance alcanzado es muy limitado, y que no es claro cuál es la relación de estas acciones con el planteamiento general de la política.

Ahora, con respecto a la institución cabeza de la política pública, y del subcomponente analizado en este artículo, se debe señalar que: no existe una unidad organizacional encargada de este componente. Y en el caso de las formulaciones de los ejes estratégicos de la entidad no se incluye este componente, lo que pone en duda la capacidad de traducir la formulación legislativa en acciones concretas. 


\section{Tabla 2}

Avances por institución con respecto al componente de generación de ingresos y empleo para población víctima del conflicto armado

\begin{tabular}{ll}
\hline \multicolumn{1}{c}{ Institución } & \multicolumn{1}{c}{ Avances } \\
\hline & Creación de grupo especial adscrito al despacho del Ministro. \\
& Asignación al presupuesto del Ministerio por el DNP $\$ 5.000$ millones \\
y la misma suma por parte del PNUD para implementación de Rutas & integrales de empleo urbano y rural para víctimas. \\
Ministerio del Trabajo & Acceso preferente a 1.285 al programa Trabajo Unido. \\
& Firma convenio con el PNUD para fortalecimiento de capacidad para \\
& implementación, seguimiento y evaluación de la política de empleo. \\
& Solicitud presupuestal para 2013 de \$48 millones. \\
\hline
\end{tabular}

17.230 hogares focalizados para pago de incentivo de retorno y reubicación.

Unidad administrativa especial para la atención y reparación integral de las víctimas
Tarea de consolidación de la oferta institucional y privada de servicios de empleabilidad y generación de ingresos para la población víctima.

Documento para la diferenciación de generación de ingresos como medida de asistencia y empleo rural y urbano en la reparación.

Oferta del $20 \%$ de formación titulada a población caracterizada como víctima.

Procedimiento para adjudicación de apoyos de sostenimiento a

SENA aprendices del SENA víctimas del conflicto.

Formación en emprendimiento y asesoría en formulación de planes de negocio a la víctimas indígenas.

Programa Jóvenes Rurales Emprendedores.

Ruta de trabajo con el SENA, DNP y Ministerio de Trabajo para la creación de una ruta de empleo urbano y rural.

Ministerio de Agricultura y Desarrollo Rural

Grupo de proyectos especiales, con acciones encaminadas al cumplimiento de las órdenes de la Sentencia T-025/04.

Grupo de trabajo de generación de ingresos y empleabilidad, que busca promover una "persona empleable"*

Fuente: elaboración propia a partir de Procuraduría General de la Nación (2012).

* En este marco se desarrollan los programas de Capitalización Microempresarial, Desarrollo Económico Incluyente, Incentivo a la Capacitación para el Empleo, Mujeres ahorradoras en acción, Mujeres productivas, Recuperación de activos improductivos, Ruta de ingresos y empresarismo, Trabajemos unidos, Enganche laboral. 
El elemento central de interés de este artículo, la relación entre la empresa privada y la política pública en la generación de empleo de la población víctima del conflicto armado, tiene su fundamento en el artículo 33 de la Ley 1448 que señala que la reparación involucra al Estado, sociedad civil y sector privado, siendo el Gobierno Nacional el encargado del diseño e implementación de programas, planes y proyectos para "involucrar a sociedad civil y empresa privada en la consecución de la reconciliación nacional y materialización de los derechos de las víctimas".

Al revisar los documentos de las acciones de las instituciones con responsabilidades en el subcomponente de Generación de ingresos y empleo se encuentra que no existe, a dos años de la puesta en marcha de la Ley, ningún plan, programa o proyecto que dé cuenta de estrategias claras para la generación de ese vínculo en la consecución de la reconciliación nacional.

El único desarrollo que se puede rastrear es la búsqueda de la Unidad de Atención y Reparación Integral a la Víctimas de proyectos de cooperación internacional, pero que en la pesquisa y revisión de información para esta investigación no presenta resultados concretos en relación con la empresa privada colombiana.

\section{Visión de los empresarios}

Para explorar cómo se ha articulado la empresa privada con la política pública de atención a la población víctima del conflicto armado, en su componente de reparación integral, subcomponente generación de ingresos y empleo, es necesario conocer las posiciones que al respecto tienen los empresarios colombianos, así como las acciones que han llevado a cabo para dar respuesta a esta disposición de tipo político reglamentaria, en un contexto de construcción de paz como el que se está gestando en la sociedad colombiana.

La ejecución de políticas públicas de interés para el empresariado, presupondría la participación de todos ellos, independientemente de su tamaño o alcance. Sin embargo, a la hora de contactar a los pequeños y medianos empresarios no se percibió mayor interés por parte de ellos para abordar la temática propuesta. A su vez, los representantes de las grandes empresas, se mostraron a favor de participar en esta investigación, por lo que 
contamos con la colaboración de Aviatur ${ }^{1}$, Pan $\mathrm{Pa}^{\prime} \mathrm{Ya}^{2}$, la Organización Ardila Lülle (en adelante $0 \mathrm{AL})^{3}$ y el Grupo Éxito ${ }^{4}$.

Las entrevistas se formularon alrededor de las siguientes variables: conocimiento de la Ley y concepción de las víctimas, acciones emprendidas por la empresa para articularse a esta Ley, articulación con el Gobierno y las Instituciones para la ejecución de la Política Pública de Reparación de Víctimas, y mecanismos e incentivos que permitan la articulación de la empresa privada. A continuación, se presentan los principales hallazgos obtenidos en cada una de las variables:

\subsection{Conocimiento de la Ley y concepción de las víctimas}

Para Jean Claude Bessudo, presidente de Aviatur el concepto de víctimas es bastante amplio. Para él, "Todos en este país somos víctimas", incluyendo a campesinos, ex combatientes, empresarios, a la sociedad en general, porque "todos nos hemos visto afectados de una u otra manera por la violencia" independientemente de dónde provenga (Comunicación personal, Jean Claude Bessudo, 20 de marzo de 2015). Para él, la mayoría de acciones que se han llevado a cabo desde la empresa privada se han centrado en los reinsertados, y en parte, se debe a lo confusa que resulta la Ley de Víctimas, que establece un marco legal, pero no una ruta puntual a seguir.

La OAL reconoce que si bien el tema de reinsertados es importante, abordar las víctimas es fundamental, pues se trata de una problemática de mayor envergadura, que la que

1 El Grupo Aviatur está conformado por 28 empresas, dedicadas al sector Turismo. Fue fundada en 1957 por su actual presidente, Jean Claude Bessudo. De acuerdo con información de la empresa, cuentan con más de 290 oficinas, distribuidas en 31 ciudades del país, y genera cerca de 4.000 empleos y representación en seis países de América y Europa.

2 Pan Pa'Ya es una cadena de Bakery Café, que nació en 1986 y que a lo largo de 29 años de existencia se posicionó como una de las empresas más importantes y representativas para el sector en Colombia. En la actualidad, la empresa genera 1.000 empleos directos y cuenta con 52 sucursales en nueve ciudades de Colombia y dos en Estados Unidos.

3 Es uno de los principales conglomerados empresariales del país. Sus empresas más representativas están en el sector de bebidas gaseosas (Postobón), el sector agroindustrial a través de ingenios azucareros, el sector de negocios y entretenimiento (RCN Radio y RCN Televisión), y distribución de vehículos, entre otros. Según la Revista Dinero (2013), para el año 2012, este grupo registró ventas superiores a los $\$ 6,3$ billones de pesos.

4 Es una de las empresas más grandes de ventas al detal en Colombia. Cuenta con 591 almacenes en todo el país, con una estrategia multimarca, a través de Almacenes Éxito, Carulla, Surtimax, y Super Inter, emplea a 41.000 personas. Además de las ventas en grandes superficies, han diversificado sus líneas de negocios con créditos de consumo, agencias de viajes, venta de seguros, industria textil y de alimentos, distribución de combustible en estaciones de servicio y una línea inmobiliaria. 
representan los reinsertados: “Conocemos la ley de víctimas. Estamos haciendo una serie de TV sobre reconciliación. Nos están apoyando (Fundaciones y 0NGs) para que el tema de víctimas quede bien plasmado en la serie" (Ana Isabel Egurrola, Comunicación personal, 8 de abril de 2015).

Por su parte Pedro Felipe Estrada, Gerente Comercial de Pan Pa'Ya, manifiesta que: "sé que existe la Ley de Víctimas, pero no la he leído o estudiado" (Comunicación personal, Pedro Felipe Estrada, 1 de abril de 2015), particularmente porque en el día a día de la empresa hay asuntos que requieren continua atención y no es posible destinar tiempo para el análisis de este tipo de leyes, en contraposición de lo que podría suceder frente a una Reforma Tributaria, por lo que Pan Pa'Ya no ha enfocado sus esfuerzos en conocer a profundidad lo propuesto por la Ley, y desarrollar alguna actividad específica que permita articularse con la reparación de víctimas.

Por último, el Grupo Éxito manifiesta conocer la ley de víctimas, y a partir de ese conocimiento han emprendido diferentes acciones que permitan articular su accionar con los parámetros dados por la Ley. A continuación, se profundizará respecto a las acciones emprendidas por el Grupo Éxito y las demás empresas.

\subsection{Acciones emprendidas por las empresas para articularse a la Ley}

Según Alexandra Rodríguez, Coordinadora de Responsabilidad Social Regional del Grupo Éxito, este conglomerado ha identificado ejes de acción muy específicos para generar aportes frente al posconflicto: “Uno de nuestros enfoques es el agro. Vemos que en Colombia hay cierto atraso en el sector agrícola. Uno de los problemas más grandes, y que tiene en crisis a este sector, es la intermediación. El presidente del Éxito nos dio la directriz de empezar a trabajar programas con miras a eliminar la intermediación, y trabajar todo lo relacionado con mercados locales y regionales (...) Empezamos con estas iniciativas hace un año y medio o dos años con las ruedas campesinas. Las hicimos a través del Ministerio de Comercio, que financió la organización de las ruedas, y el Éxito llevó a sus negociadores a diferentes regiones y se hicieron ruedas de negocios, que permitieron codificar cerca de 80 proveedores, en regiones como Cundinamarca, Boyacá, Nariño, Santander, Córdoba y Cauca, entre otros" (Alexandra Rodríguez, Comunicación personal, 20 de abril de 2015).

En el desarrollo de estas acciones, el Grupo se ha enfocado en campesinos en situación vulnerable, lo que incluye trabajo con víctimas, desplazados, desmovilizados y población en extrema pobreza. Asumen que con miras al posconflicto, y desde el agro, la idea 
es generar capacidades en la población para vincularlos a su cadena de proveedores, y disminuir brechas para la construcción de tejido social: "Para hacer más atractiva la negociación con los campesinos, en el programa de No Intermediación, ofrecemos pagos con condiciones muy diferentes a las que suele manejar el Éxito con sus proveedores (a ocho días, en contraposición a las condiciones de 30,60 o 90 días con los proveedores tradicionales)" (Alexandra Rodríguez, Comunicación personal, 20 de abril de 2015).

Para la generación de capacidades, han optado por capacitación productiva frente a la calidad, y en negociación, para que independientemente de su vinculación con el Éxito, el campesino esté en capacidad de negociar con grandes superficies. Según Mariana ViLlamizar, Jefe de gobierno, sostenibilidad y responsabilidad social del Grupo Éxito, "La idea es que los campesinos se puedan formalizar, pues es la única manera de garantizar que se estructuren proyectos sostenibles a largo plazo" (Mariana Villamizar, Comunicación personal, 20 de abril de 2015).

Adicionalmente, el Grupo Éxito trabaja con Campo Vivo en asocio con McCain, con familias campesinas productoras de papa en Cundinamarca y Boyacá, en condiciones de extrema pobreza. La idea es que se conviertan en proveedores de papa del Grupo Éxito, a través de compras que van de 50 a 60 toneladas, con posibilidades de incrementar los pedidos, en función de la capacidad de los productores.

Frente al tema de empleabilidad, trabajan con población vulnerable (ex combatientes, víctimas, jóvenes en riesgo, discapacitados y fuerzas armadas). En la actualidad, tienen vínculo laboral con 400 personas provenientes de estas poblaciones, sin embargo, prefieren guardar prudencia para evitar la estigmatización: “La reinserción debe pasar por no tratar al otro con una etiqueta que resalte su condición de víctima o de reinsertado" (Mariana Villamizar, Comunicación personal, 20 de abril de 2015). Sin embargo, la empleabilidad no es uno de sus enfoques principales, ni el que mayor impacto pueda generar, por lo que prefieren concentrar esfuerzos en la generación de capacidades.

Esta visión es apoyada por Ana María Guerrero, Gerente de Responsabilidad Social de la $O A L$, pues la empleabilidad resulta un eje complejo de atender por el empresariado: “Hemos dado muchas vueltas de cómo ayudar al tema del posconflicto. Frente a los desmovilizados, no ha sido fácil. El temor a emplear desmovilizados es generalizado, sumado a que la capacidad de absorber, y de emplear es mínima" (Ana María Guerrero, Comunicación personal, 8 de abril de 2015). A pesar de ser uno de los grupos empresariales más gran- 
des, su capacidad de absorción no es realmente representativa, por lo que sería mejor pensar en actuar sobre otros ejes, que generen capacidades sostenibles en el tiempo.

Al respecto, la OAL está desarrollando programas con población vulnerable (campesinos, víctimas y desmovilizados), para incluirlos como parte de su cadena de proveedores: “En los ingenios ya lo estamos haciendo. Tenemos varios ejemplos: un programa de proveedores de fruta para Postobón donde priorizamos los campesinos que tienen menos de una hectárea y les ayudamos en el tema técnico. Tenemos otra experiencia en el Valle con una empresa de desmovilizados" (Ana María Guerrero, Comunicación personal, 8 de abril de 2015).

Algunas de las dificultades encontradas en este proceso, tienen que ver con la capacidad de organización de los diferentes grupos, pues al tratarse de compras de insumos de gran volumen, que requieren procesos y estándares de calidad específicos, hace falta organización a través de asociaciones campesinas, que garanticen una acción conjunta que permita una integración efectiva en la cadena de proveedores. La idea que tiene la OAL a través de estas actividades, es generar capacidades y eliminar intermediarios para aumentar el margen de ganancias de los productores.

Por último consideran importante visibilizar el trabajo que se ha hecho con las víctimas, y su situación. Al respecto, se sirven de las empresas de medios de comunicación (RCN Radio y RCN Televisión). Ana Isabel Egurrola del Equipo de responsabilidad social empresarial de la OAL, comenta que en el noticiero se realizaron algunas crónicas que visibilizaban la situación de las víctimas en su proceso de reparación, "porque la solución al conflicto no pasa solamente por lo que pase en las negociaciones con la guerrilla, sino que se da en otros espacios, y por eso mismo, la reconciliación se puede estar dando ya en muchos otros frentes que deben ser visibilizados" (Ana Isabel Egurrola, Comunicación personal, 8 de abril de 2015).

Por su parte, Jean Claude Bessudo del Grupo Aviatur ha desarrollado hasta el momento un trabajo de vinculación laboral de reinsertados en el Tayrona: "Allí tenemos varios empleados que son reinsertados. No sé decirte cuáles son, ni los diferencio. No les pongo una etiqueta de reinsertados" (Comunicación personal, Jean Claude Bessudo, 20 de marzo de 2015). Sin embargo, considera que puede haber cierta prevención de los empresarios para recibir personas y vincularlas laboralmente, debido a su pasado, y a los estigmas que se pueden generar alrededor de ellos. 
Considera importante que se avance en el desarrollo de proyectos turísticos con población campesina y reinsertados, particularmente en aquellas regiones afectadas por el conflicto, como la Macarena o la Sierra Nevada de Santa Marta. Para Bessudo, “siempre y cuando tengamos una buena infraestructura, se pueden desarrollar proyectos con personas de las regiones" (Comunicación personal, Jean Claude Bessudo, 20 de marzo de 2015), asumiendo que los incentivos para el sector turístico, también están en función de las condiciones dadas por el Gobierno y las Instituciones.

Para Pedro Felipe Estrada de Pan Pa'Ya, muchos de los esfuerzos del empresariado en general se han concentrado en el tema de reinsertados. Sin embargo, "en el tema de reinsertados, en el fondo son pocos. Hoy no hay más de 12.000 guerrilleros -pienso yo-, pero en un país de 48 millones de habitantes, no son muchos. Es el equivalente de una empresa grande. Las víctimas son el número realmente grande, son al menos 5 millones de víctimas, incluyendo a los desplazados" (Pedro Felipe Estrada, Comunicación personal, 1 de abril de 2015), lo que da unas dimensiones muy diferentes de la problemática que la sociedad colombiana tiene por delante.

\subsection{Percepción de la articulación con el Gobierno y las Instituciones}

Respecto a la articulación con el Gobierno, el presidente del Grupo Aviatur considera que “en este país se confunde el discurso con la acción" (Jean Claude Bessudo, Comunicación personal, 20 de marzo de 2015), por lo que se generan muchos discursos respecto a la solución del conflicto, pero no se dan acciones concretas. En función de esto, muchas de las iniciativas de atención a víctimas se quedan en propuestas que no pueden ser llevadas a la práctica por falta de planes de acción, liderados por el Gobierno Nacional.

En ese contexto, las actividades emprendidas por la OAL son resultado de la iniciativa propia, y han estado orientadas a atender la población que se ha visto afectada por la dinámica propia del conflicto armado. En la actualidad, la OAL desarrolla un trabajo con la Agencia Nacional para la Reconciliación (ACR) con desmovilizados. Sin embargo, respecto a las víctimas no hay un trabajo articulado con el Gobierno, sino con fundaciones que se enfocan en esta población.

A diferencia de los casos anteriormente expuestos, el Grupo Éxito se ha logrado articular con instituciones como el Ministerio de Comercio, a través de uno de los viceministerios, recibiendo apoyo al proceso de ruedas de negocios. Sin embargo, se han visto afectados por el nombramiento de nuevos funcionarios y por cambios en el Ministerio, que han es- 
tancado los procesos, lo que evidencia que en este caso particular, el apoyo institucional no parece hacer parte de una política sino de la intencionalidad de los funcionarios a cargo. Por esto, para el Grupo Éxito, “los incentivos tributarios no son realmente determinantes. Es más importante la intencionalidad política y la disposición institucional" (Mariana Villamizar, Comunicación personal, 20 de abril de 2015).

Esto lleva a identificar debilidades institucionales, ratificadas por el Gerente Comercial de $\mathrm{Pan} \mathrm{Pa}^{\prime} \mathrm{Ya}$, quien considera que es fundamental iniciar la articulación empresa - gobierno, pues "Las empresas somos un medio para resolver muchos problemas del país pero si no trabajamos en equipo con el Estado, se dificulta el asunto" (Pedro Felipe Estrada, Comunicación personal, 1 de abril de 2015). A su vez, manifiesta que "el problema es de todos los colombianos, y necesitamos un país desarrollado. El desarrollo del país pasa por resolver éste y otros problemas, y para esto, tiene que haber una alianza público privada, entre el Estado y las empresas. Soy un convencido de que las empresas jugamos un papel muy importante en la sociedad, es un papel dinamizador, que genera desarrollo. Tiene que haber iniciativas de lado y lado: el Estado generando todos los mecanismos y las condiciones institucionales, y de las empresas, el interés para participar" (Pedro Felipe Estrada, Comunicación personal, 1 de abril de 2015).

Manifiesta su preocupación respecto al interés general del empresariado para articularse a este tipo de iniciativas: "El interés general (de los empresarios), no lo siento". Hay unos empresarios que tienen consciencia sobre la Responsabilidad Social, y este es un medio para poder articular esfuerzos y aportar a la solución de estos problemas: "Nada será sostenible si no aportamos al país" (Pedro Felipe Estrada, Comunicación personal, 1 de abril de 2015). Adicionalmente, hizo énfasis en la estructura empresarial colombiana, que en su mayoría está compuesta por Pymes, lo que dificulta su accionar respecto a esta problemática, pues el enfoque en lo cotidiano de la empresa, en el día a día, es mucho más notorio en este tipo de empresas, lo que dificulta su vinculación a estas iniciativas.

Para él, hay problemas de liderazgo que impiden que haya una unidad de dirección, y esto se traduce en falta de claridad para generar lineamientos de acción, que nos lleven a una acción conjunta como sociedad: “La mayoría de los colombianos queremos la paz, vivir mejor y tener mejor calidad de vida. Pero lo queremos en abstracto, y cuando tenemos que trabajar para eso y comprometernos con esto, y renunciar a algo para lograrlo, se dificulta este proceso" (Pedro Felipe Estrada, Comunicación personal, 1 de abril de 2015). 


\section{Mecanismos e incentivos para articularse a la Ley de Víctimas}

Jean Claude Bessudo de Aviatur, considera que además de planes de acción concretos que evidencien los mecanismos de articulación de la empresa privada a las iniciativas de reparación de víctimas, se deben estructurar mecanismos que impulsen a la empresa a liderar iniciativas en este sentido: "Se podría destinar un porcentaje de los impuestos que debe pagar la empresa, para la financiación, por ejemplo, de proyectos productivos" (Jean Claude Bessudo, Comunicación personal, 20 de marzo de 2015).

Esta iniciativa es apoyada por Pedro Felipe Estrada de Pan Pa'Ya, quien cree que el Gobierno puede lograr que el empresariado se comprometa a aportar a través de beneficios tributarios, pero sobre todo, desplegando mecanismos que garanticen una gran convocatoria: "se debe llamar a las empresas, y organizarlas. Comunicar y promover los espacios para que las empresas participen, y que esto no se quede en que el estímulo existe, porque el estímulo por sí sólo no funciona" (Pedro Felipe Estrada, Comunicación personal, 1 de abril de 2015).

Considera que para el apoyo a las víctimas del conflicto desde las empresas, existen dos caminos: Emprendimiento y Empleo. El emprendimiento genera capacidades y permite sostenibilidad a largo plazo, pero requiere procesos de formación muy serios. Es difícil generar impactos muy grandes a partir del empleo, porque la capacidad de empleabilidad, incluso de las empresas muy grandes, no es realmente significativo frente a la cantidad de personas que deben ser cubiertas por estos programas. Por este motivo cree que los incentivos se deben centrar en el apoyo a la generación de capacidades que permitan emprendimientos sostenibles.

Para los representantes de la OAL es fundamental establecer incentivos desde el Gobierno (bien sean tributarios, apoyo institucional, entre otros), pero aseguran que deben estructurarse adecuadamente para que se ofrezcan de tal manera que se tenga claridad acerca del grupo de beneficiarios y de los posibles réditos que la oferta del incentivo va a generar, "por ejemplo, la ley para vincular discapacitados termina configurando incentivos perversos" (Ana Isabel Egurrola, Comunicación personal, 8 de abril de 2015).

El Grupo Éxito considera que en este momento se puede percibir que cada empresa está haciendo sus propios esfuerzos de forma aislada, y sin ningún tipo de orientación clara para articularse: “cuando venga el posconflicto habrá modificaciones, habrá reformas que deberán formularse y se tendrá que pagar más impuestos para lograr abordar el pos- 
conflicto" (Mariana Villamizar, Comunicación personal, 20 de abril de 2015), y en consecuencia, las empresas deberán desarrollar estrategias y acciones conjuntas para lograr actividades de impacto. Más allá de las articulaciones que se den por iniciativa propia de la empresa privada, no identifican la necesidad de generar estímulos adicionales, pues estos incentivos ya existen y son efectivos.

\section{Conclusiones}

Las conclusiones de este artículo se estructuran en dos sentidos: en primer lugar, respecto a los hallazgos de las entrevistas, evidenciando convergencias y divergencias entre las concepciones y las acciones emprendidas por las empresas frente a la Ley de Víctimas. Por otra parte, a partir de esos hallazgos, se concluirá respecto a los posibles campos de acción que se tienen desde el ámbito de la Administración para apoyar procesos efectivos en el sector empresarial de cara al posconflicto.

Respecto al conocimiento de la Ley de Víctimas, se puede decir que los empresarios desconocen -en detalle- los componentes de la Ley de Víctimas y en consecuencia, las acciones que realizan desde sus empresas están en función de los parámetros de la Responsabilidad Social Empresarial, pero no se encuentran alineadas, necesariamente, con los ejes establecidos por la política pública respecto a víctimas.

Las empresas han actuado bajo tres ejes fundamentales para trabajar y generar aportes frente a la situación de las víctimas:

- Donaciones o articulación con Fundaciones para trabajar con comunidades de población vulnerable (esto puede incluir o no a la población víctima del conflicto).

- Empleabilidad: respecto a este factor, los empresarios coinciden en que la generación de empleo no es una alternativa que lleve a una sostenibilidad en el largo plazo. Sumado a esto, consideran que las empresas no tienen capacidad para generar un gran impacto con la generación de empleo, dado que su capacidad de absorción laboral, no permitiría incluir a una gran parte de la población víctima del conflicto, lo que llevaría a establecer procesos excluyentes.

- Generación de capacidades (emprendimientos): esta parece ser la alternativa que resulta más atractiva para los empresarios. Consideran que la generación de capacidades permite establecer acciones que generan cambios estructurales en las condiciones económicas de la población víctima, y permiten ejercicios de asociatividad. 
En algunas de las entrevistas se puede vislumbrar que para ciertas empresas, los emprendimientos pueden llevar a capacitaciones conjuntas de población víctima, desplazados y reinsertados, lo que puede abrir el camino para generar espacios de integración y reconciliación.

La idea de la mayoría de las personas entrevistadas es que, a través de la generación de capacidades que redunden en procesos de emprendimiento, se puedan generar alianzas para vincular a campesinos y víctimas como parte de su cadena de proveedores, eliminando intermediarios y estableciendo relaciones de largo plazo que por una parte, impulsarían los emprendimientos en el momento de nacimiento de las nuevas empresas, y en el que están más expuestas a riesgos que las lleven a su desaparición. Por otra, la eliminación de estos intermediarios, representa una disminución en la estructura de costos para cada una de las empresas, y le permite tener un mayor nivel de control sobre su cadena de producción.

Sobre la articulación con el Gobierno e Instituciones, las empresas no perciben que exista una articulación clara. La mayoría encuentra que existen políticas públicas, que al no traducirse en planes de acción concretos, dificultan la articulación de ellos a cada uno de los programas, reduciendo su capacidad para aportar en la materialización de lo establecido en las políticas.

Acerca de los mecanismos e incentivos, las empresas destacan la importancia de establecer incentivos que vinculen a los empresarios. Se habla de incentivos de tipo tributario particularmente, y que permitan soportar el desarrollo de emprendimientos por parte de la población víctima, tal como lo propuso Jean Claude Bessudo de Aviatur. Sin embargo, el Grupo Éxito indica que es preferible que el incentivo pase más por un apoyo institucional fuerte, que permita consolidar los procesos que ellos llevan a cabo.

Muchos empresarios reconocen la importancia de atender a los desmovilizados y reinsertados, pero no hay una visión más global de la problemática, que le apunte a ofrecer programas prioritarios enfocados en víctimas. Tal como lo mencionó el Gerente Comercial de Pan Pa'Ya, la población de víctimas es numerosa y requiere mayores niveles de atención por parte del Gobierno y la empresa privada.

Por otra parte, se puede observar que la mayoría de empresas asume su aporte a la política pública de atención a víctimas, desde un punto de vista esencialmente económico. Si bien la generación de ingresos es fundamental para garantizar las oportunidades para 
la población víctima, el proceso debe ser integral, y no se debe olvidar que las respuestas estratégicas que ofrece la empresa no deben centrarse en dar una única respuesta al aspecto que genera modificaciones en el entorno, pues los demás factores también deben ser impactados: en este caso, el político, el social y el cultural, principalmente, asumiendo que el económico está siendo cubierto.

En ese contexto, la visibilidad de las víctimas es importante dentro del proceso de reconciliación. Entre los casos estudiados, la OAL evidencia acciones al respecto, apoyado en la infraestructura que lo sostiene como grupo empresarial, y en la diversidad de sectores que cubre.

Por otra parte, desde la Administración se debe propender porque las empresas trasciendan sus programas de Responsabilidad Social Empresarial. Estos no pueden seguir estando estructurados en función de la atención a necesidades puramente coyunturales. La sociedad colombiana requiere que desde la Administración se impulse la creación -y estructuración- de empresas socialmente responsables, para que las empresas generen respuestas que aporten a las necesidades sociales desde cada una de sus actividades. Esto implica que se estudien diversos aspectos: la gestión del factor humano, los procesos productivos, comercio justo e impacto ambiental, entre otros.

Si se pretende que las organizaciones empresariales sean un eje fundamental en la generación de crecimiento económico y la construcción de una sociedad justa, es necesario generar aportes efectivos desde la academia y el empresariado. Se requieren cambios en la forma de gerenciar las empresas, y en el proceso formativo de quienes estarán a cargo de hacerlo. Esto implica trascender la concepción de la empresa como una unidad económica, para comprender que tiene una función social, lo que implica ir más allá de la búsqueda de rendimientos financieros, y emprender acciones que generen impacto social.

El reto para la Administración en Colombia consiste en generar vínculos entre la academia y la empresa, que le permitan estructurar mecanismos y herramientas de gestión acordes a las necesidades de las empresas en un entorno como el colombiano. La academia debe estar en constante disposición de realizar actividades de investigación conducentes a determinar las necesidades de la sociedad y de las empresas, así como también a generar respuesta efectiva a estas. Por su parte, las empresas deben estar en disposición de articularse con las propuestas surgidas desde el ámbito académico, generando no sólo un impacto económico sino también social. 


\section{Referencias}

ACNUR (2008). Guía para la incorporación de la prevención y atención al desplazamiento forzado en los planes de desarrollo territorial. Bogotá: Acción Social.

Benhamu, S., et Le Garrec, G. (2005). Organisation de l'entreprise et complexité de l'environnement: une estimation sur données françaises. Documents de Travail de l'0FCE 2005-14. Observatoire Français des Conjonctures Economiques (OFCE).

Bertalanffy, L. (1989). Teoría General de Sistemas. México D.F.: Fondo de Cultura Económica. CODHES (2015). Grupos pos-desmovilización y desplazamiento forzado en Colombia: una aproximación cuantitativa. Recuperado el 2 de septiembre de 2015, de: http://www.codhes. org/ codhes/images/Articulos/GPD_y_desplazamiento_forzado_en_Colombia.pdf

Contraloría General de la Nación (2012). Auditoría a la política pública para el desplazamiento forzado por la Violencia, componente de estabilización socioeconómica, subcomponentes de vivienda, tierras y generación de ingreso (2007-2011). Bogotá.

Corte Constitucional de Colombia (2004). Sentencia T-025/04. Bogotá. Recuperada el 2 de abril de 2015, de: http://www.corteconstitucional.gov.co/relatoria/2004/T-025-04.htm

DNP (2011). CONPES 3712 de 2011. Plan de Financiación para la Sostenibilidad de la Ley 1448 de 2011. Bogotá: DNP.

DNP (2012). CONPES 3736 de 2012. Lineamientos, plan de ejecución de metas, presupuesto y mecanismo de seguimiento para el Plan Nacional de Atención y Reparación Integral a Víctimas. Bogotá: DNP.

Etkin, J. y Schvarstein, L. (2005). Identidad de las organizaciones: invarianza y cambio. Buenos Aires: Editorial Paidós.

Ferrandon, B. (2004). Comprendre le management. Cahiers Français, 321, julio - agosto.

Forester, J. (1989). Planning on the face of power. Los Angeles: University of California Press.

Forester, J. (1993). Critical theory, public policy and planning practice. Toward a critical pragmatism. Albany: State University of New York.

Forester, J. (2009). Dealing with differences: dramas of mediating public disputes. 0xford: 0xford University Press.

Gómez, J. (2015). El derecho de las víctimas al trabajo, la formación y la generación de ingresos. Recuperado el 1 de abril de 2015, de: http://viva.org.co/cajavirtual/svc0387/articulo03.html

Herazo, G. y Sellamén, A. (2010). El programa de generación de ingresos y el desplazamiento forzado. Criterio libre, 8 (13), 129-169.

Krieger, M. (2001). Sociología de las organizaciones. Buenos Aires: Prentice Hall.

Lam, A. (2010). Innovative organizations: Structure, learning and adaptation. Innovation Perspectives for the 21st Century (pp. 163-175). Madrid: BBVA. 
Lemaire, J. P. (1997). Stratégies d'internationalisation. Paris : Dunod.

López, P. y Mariño, A. (2010). Hacia una evolución en el campo del conocimiento de la disciplina administrativa: De la administración de empresas a la gestión de organizaciones. Revista Facultad de Ciencias Económicas Universidad Militar Nueva Granada, XVIII (2), 75-93.

Morgan, G. (1999). Images de l'organisation. Canada: Les Presses de l'Université Laval.

Navarro, J. (2000). Gestión de organizaciones: Gestión del caos. Revista Dirección y Organización. Universidad Politécnica de Madrid, 23, 136-145.

Procuraduría General de la Nación (2012). Seguimiento al cumplimiento de las medidas en materia de empleo urbano y rural para las víctimas. Bogotá.

Revista Dinero (2013). Grupo Ardila. Recuperado el 10 de abril, de: http://www.dinero.com/ edicion-impresa/caratula/articulo/grupo-ardila/177564

Revista Semana (2 de febrero de 2014). Seis millones de víctimas deja el conflicto en Colombia. Recuperado el 2 de septiembre de 2015, de: http://www.semana.com/nacion/articulo/ victimas-del-conflicto-armado-en-colombia/376494-3

Rodríguez, C. y Duque, J. (2007). Seguimiento a la dinámica competitiva de dos grupos económicos colombianos. Revista Innovar, 17 (29), 137-154.

Rodríguez, C. y Duque, J. (2008). El Grupo Santodomingo: el pez chico se come al pez grande de generación en generación. Revista Innovar, 18 (32), 127-152.

Roth, A. N. (2003) Introducción para el análisis de políticas pública. Cuadernos de Administración Univalle, 19 (30), 114-128.

Silva, J. S. y Valencia, M. (2013). Encuentros y desencuentros en Gustavo Rojas Pinilla y Álvaro Uribe Vélez. Revista Javeriana: El pensamiento cristiano en diálogo con el mundo. Medio ambiente universal y desarrollo Sostenible, 149 (795), 60-68.

Sonntag, M. (2010). De l'école à l'entreprise un entre-deux oublié du travail collectif. Travail et formation en éducation. En línea, No. 7. Recuperado el 2 de abril de 2015, de: http:// tfe.revues.org/1513

Tapia, E. M. (2012). Gestión por políticas. Análisis de los planos de acción en que se desenvuelve la implementación de una política pública. Pensamiento Jurídico, 34, 103-134.

Velásquez, F. (2002). Escuelas e interpretaciones del pensamiento administrativo. Estudios Gerenciales, 18 (83), 31-55. 
